
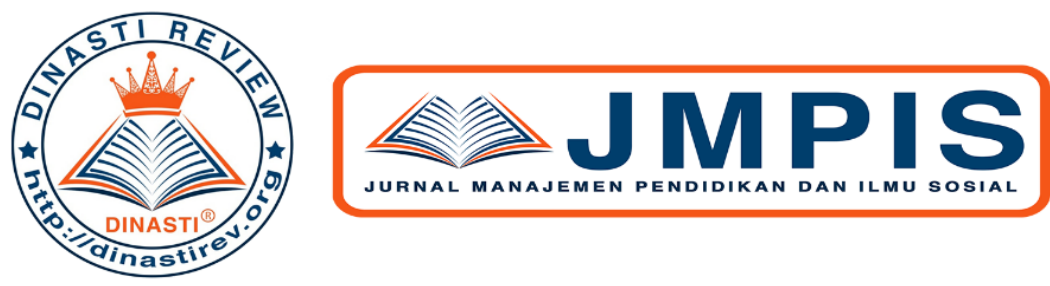

+6281387654578

+6281387654578@

https://dinastirev.org/JMPIS (8)

dinasti-info@gmail.com G.

\title{
PENERAPAN BALANCED SCORECARD PADA DEPARTMENT HUMAN RESOURCES MANAGEMENT PT XYZ
}

\section{Anggun Maharani}

Universitas Mercubuana, Jakarta, Indonesia

ARTICLE INFORMATION

Received: 23 Mei 2020

Revised: 30 Mei 2020

Issued: 1 Juni 2020

Corresponding author: first author

E-mail:

ia_anggun@yahoo.com

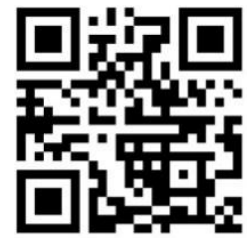

DOI:10.38035/JMPIS
Abstrak: Balanced Scorecard adalah salah satu sarana dalam pengukuran kinerja dalam sebuah organisasi. Balanced Scorecard mampu menterjemahkan pencapaian visi dan misi perusahaan dengan menggunakan 4 persepktif yaitu Keuangan, Pelanggan, Proses Bisnis Internal serta Pembelajaran dan Pertumbuhan. Pengukuran kinerja menjadi salah satu hal yang penting dalam sebuah perusahaan agar perusahaan dapat melakukan analisa dan pengukuran terkait dengan aktitas-aktifitas strategi serta memonitor kinerja strategi dalam usaha pencapaian visi dan misi perusahaan. Penelitian ini bertujuan untuk melakukan analisa penerapan Balanced Scorecard dalam pengukuran kinerja department Human Resources Management pada PT XYZ serta melakukan evaluasi strategi yang telah dilakukan, agar strategi yang ada dapat mendukung pelaksanaan visi misi department. Selain itu penelitian ini bertujuan untuk dapat memberikan evaluasi pada strategi yang sudah ada serta memberikan masukan terkait dengan strategi lain yang mungkin dapat dilakukan dalam Department Human Resources Management agar dapat mengakomodir pelaksanaan visi misi perusahaan dengan optimal. Metode penelitian yang digunakan adalah deskriptif kualitatif agar dapat memeberikan gambaran terkait dengan pelaksanaan Balanced Scorecard dengan terperinci.

Kata Kunci: Balanced Scorecard, Human Resources Management.

\section{PENDAHULUAN}

Dalam menghadapi persaingan dunia usaha yang sangat kompetitif, tentunya perusahaan ingin mempunyai strategi yang sesuai dengan kebutuhan perusahaan sehingga perusahaan mampu menghadapi persaingan kompetitif dan bertahan dalam pasar. Penetapan strategi dalam suatu perusahaan menjadi hal yang sangat penting dalam mencapai tujuan perusahaan, namun 
tentunya strategi tersebut harus selaras dengan visi dan misi dalam suatu perusahaan. Dalam pelaksanaan suatu strategi perusahaan perlu dilakukan pengukuran keberhasilan setiap aktifitas yang dilakukan untuk menjalankan strategi tersebut, sehingga perusahaan dapat mengevaluasi keberhasilan suatu strategi, pencapaian kinerja perusahaan serta mendukung pembuatan suatu kebijakan dalam suatu perusahaan.

Pengukuran kinerja dalam suatu perusahaan biasanya dilakukan untuk menganalisa pencapaian suatu aktifitas strategi terhadap target yang ditetapkan. Aktifitas strategi yang dilakukan dalam sebuah perusahaan dapat dilakukan oleh semua department dalam perusahaan tersebut ataupun hanya sebagian department berdasarkan fungsi masing-masing department dalam sebuah perusahaan.

Salah satu alat yang biasa digunakan dalam pengukuran suatu strategi adalah Balanced Scorecard. Balanced Scorecard atau BSC merupakan suatu sistem manajemen strategi (Strategic Based Responsibility Accounting System) yang menjelaskan mengenai misi serta strategi dari suatu perusahaan ke dalam tujuan operasional dan tolok ukur kinerja perusahaan tersebut, Hapzi (2016). Dalam konsep Balanced Scorecard ini akan melihat keseimbangan kinerja dalam sebuah organisasi melalui 4 persektif yaitu Keuangan, Pelanggan, Proses Bisnis Internal serta Pembelajaran dan Pertumbuhan. Dengan menggunakan keempat perspektif ini diharapkan pengukuran kinerja dapat dilakukan dengan menyeimbangkan aktifitas strategi kedalam keempat perspektif tersebut sehingga perusahaan mampu merencanakan dan mengelola strategi perusahaan dengan lebih baik. Dengan pelaksanaan penilaian kinerja menggunakan konsep Balanced Scorecard, perusahaan tidak hanya bisa melihat kinerja organisasi secara keseluruhan, namun juga dapat melihat kinerja setiap department dalam pelaksanaan dan pencapaian suatu strategi.

Oleh karena itu dalam artikel ini akan dibahas Penerapan Balanced Scorecard Pada Department Human Resources Management pada PT XYZ. PT XYZ adalah perusahaan yang bergerak dalam distribusi alat kesehatan yang berfokus dalam distribusi produk diagnostik. Dalam menjalankan bisnisnya PT XYZ mempunyai 31 titik distribusi yang menjadi jaringan distribusi yang berkembang di seluruh wilayah Indonesia, dengan cakupan area yang cukup luas di seluruh wilayah Indonesia ini menjadikan PT XYZ memerlukan strategi bisnis yang sesuai dengan kebutuhan perusahaan agar mampu bersaing dengan pasar yang ada. Dalam menjalankan operasional perusahaan, PT XYZ membagi kedalam fungsi department berdasarkan fungsi dan peran yang saling mendukung kegiatan operasional perusahaan. Dalam menjalankan masingmasing fungsinya, setiap department memerlukan strategi dalam pencapaian tujuan serta evaluasi terhadap masing-masing strategi maupun kegiatan yang dijalankan.

Salah satu department yang mempunyai peran yang sangat penting dalam pencapaian strategi adalah Department Human Resources Management, karena department ini memiliki fungsi untuk melakukan pengembangan sumber daya manusia. Dimana hal tersebut menjadi salah satu permasalahan utama dalam perusahaan untuk dapat mengembangkan sumber daya manusia sesuai dengan perkembangan bisnis serta agar perusahaan mampu menghadapi persaingan bisnis dengan kompetitor. Oleh karenanya faktor sumber daya manusia menjadi salah satu perhatian perusahaan, sehingga pelaksanaan strategi dalam Department Human Resources Management mendapatkan perhatian yang cukup besar untuk dapat dievaluasi dan dianalisa. Sehingga perusahaan mampu membuat seuatu kebijakan maupun pengembangan strategi apabila strategi yang ada belum sesuai atau belum mampu mendukung visi misi perusahaan maupun visi misi department terkait. 


\section{KAJIAN PUSTAKA}

Menurut Kaplan dan Norton (1996), Balanced Scorecard merupakan alat pengukur kinerja eksekutif yang memerlukan ukuran komprehensif dengan empat perspektif, yaitu perspektif keuangan, perspektif pelanggan, perspektif bisnis internal, dan perspektif pertumbuhan dan pembelajaran. Sementara itu Anthony, Banker, Kaplan, dan Young (1997) mendefinisikan Balanced Scorecard sebagai: "a measurement and management system that views a business unit's performance from four perspectives: financial, customer, internal business process, and learning and growth."

Balanced Scorecard atau BSC merupakan suatu sistem manajemen strategi (Strategic Based Responsibility Accounting System) yang menjelaskan mengenai misi serta strategi dari suatu perusahaan ke dalam tujuan operasional dan tolok ukur kinerja perusahaan tersebut.

Balanced Scorecard merupakan suatu kartu skor yang digunakan untuk merencanakan skor yang hendak diwujudkan oleh seseorang di masa depan, dan untuk mencatat skor hasil kinerja yang sesungguhnya dicapai oleh seseorang (Munawir 2002: 437).

Menurut Maria (2012), metode balanced scorecard sangat penting digunakan dalam penerapan strategi perusahaan agar perusahaan mampu merancang sekaligus menilai berbagai strategi yang cocok untuk dijalankan oleh perusahaan.

Balanced scorecard memiliki beberapa kegunaan, yaitu: mengklarifikasi dan menghasilkan konsesus tentang strategi; menyelaraskan berbagai tujuan departemen dan pribadi dengan strategi perusahaan; mengaitkan berbagai tujuan strategik dengan sasaran jangka panjang dan anggaran tahunan; mengidentifikasikan dan menyelaraskan berbagai inisiatif strategik; mendapatkan umpan balik yang dibutuhkan untuk mempelajari dan memperbaiki strategi (Tunggal, 2002: 22).

Balanced Scorecard memiliki keunggulan yang menjadikan sistem manajemen strategik saat ini berbeda secara signifikan dengan sistem manajemen strategik dalam manajemen tradisional (Mulyadi,2001).

Perspektif dalam Balanced ScoreCard :

1. Perspektif Keuangan (Finance)

Balanced score card menggunakan indicator kinerja keuangan yang secara umum dipakai oleh perusahaan, seperti laba bersih dan ROI (return on investment. Meskipun demikian indicator tersebut tidak berdiri sendirii tanpa adanya dukungan dari aspek lain. Sesuai prinsip dalam BSC harus ada keseimbangan antara perspektif keuangan dan perspektif non keuangan.

2. Perspektif Pelanggan (Customer)

Dalam perspektif ini, yang pertama kali harus dilakukan oleh perusahaan adalah penentuan segmen pasar pelanggan yang akan menjadi target yang ingin disasar oleh perusahaan.

3. Perspektif Proses Bisnis Internal (Internal Business Process)

Perspektif proses bisnis internal merefleksikan proses-proses kunci di perusahaan yang dapat dioptimalkan yang dapat meningkatkan value proposisi yang dapat menarik dan mempertahankan pelanggan. 
4. Perspektif Pembelajaran dan Pertumbuhan (Learning and Growth)

Perspektif pembelajaran dan pertumbuhan merefleksikan kapabilitas perusahaan dalam mengembangkan 3 jenis sumber daya atau capital sebagai berikut:
a. Human Capital
b. Organizational Capital
c. Information Capital

\section{METODE PENELITIAN}

Metode penelitian yang digunakan dalam pembuatan tugas ini adalah deskriptif kualitatif. Penelitian deskriptif kualitatif adalah penelitian yang menggambarkan atau melukiskan objek penelitian berdasarkan fakta-fakta yang tampak atau sebagaimana adanya. Nawawi dan Martini (1996: 73). Dengan menggunakan deskriptif kualitatif diharapkan peneliti dapat menyampaikan informasi dengan melakukan pemaparan serta memberikan fakta - fakta yang diperlukan agar dapat melakukan Analisa Balanced Scorecard dan memperoleh kesimpulan sesuai dengan hasil analisa yang dilakukan. Dalam hal ini subjek penelitian adalah PT XYZ dan objek yang akan diteliti adalah penerapan Balanced Scorecard pada Department Human Resource Management PT XYZ.

\section{HASIL \& PEMBAHASAN}

\section{Profil Perusahaan}

PT XYZ adalah perusahaan yang bergerak di bidang distribusi alat kesehatan yang sebagian besar bisnisnya berfokus kepada distribusi produk - produk diagnostik atau alat-alat kesehatan yang digunakan pada laboratorium. Adapun jenis alat - alat laboratorim yang biasa dipasarkan meliputi pemeriksaan urine, koagulasi, kimia klinik, immunologi, analisa gas darah, elektrolit, hematology, dan saat ini telah mengembangkan usaha dalam penyediaan alat rotgen.

Sebagai perusahaan distribusi alat kesehatan tentunya PT XYZ selalu berusaha untuk dapat bekerjasama dengan pricipals yaitu perusahaan yang mempunyai produk-produk alat kesehatan yang memiliki kualitas produk yang baik serta memiliki kebutuhan pasar.

Dengan analisa kebutuhan pasar yang ada di Indonesia PT XYZ telah berusaha melakukan pelayanan kepada konsumen yang merupakan Rumah Sakit baik Swasta maupun Pemerintah, Klinik, Dinas Kesehatan, Pusat Kesehatan Masyarakat/PKM maupun Laboratorium. Dengan jumlah persebaran sekitar Rumah Sakit meliputi Rumah Sakit Pemerintah sebanyak 948 site dan Rumah Sakit Swasta sebanyak 1.821 site. Selain itu dengan jumlah Dinas Kesehatan sebanyak 504 sites, Pusat Kesehatan Masyarakat/PKM Pemerintah sebanyak 3.459 site dan Pusat Kesehatan Masyarakat/ PKM Non Pemerintah sebanyak 6.376 sites.

Untuk dapat mencukupi kebutuhan pasar yang ada di Indonesia, PT XYZ mengembangkan bisnis menjadi 25 titik distribusi yang tersebar diseluruh Indonesia serta mempunyai subsidiary company dengan nama PT XYZJ dengan 6 titik distribusi yang tersebar di wilayah Sumatera. Setiap titik distribusi diharapkan dapat mengakomodir kebutuhan produk alat kesehatan dalam lingkup Kabupaten maupun Propinsi di Indonesia dilihat dari persebaran dan jumlah Rumah Sakit di masing-masing wilayah tersebut.

Dalam pengaturan Struktur Organisasi PT XYZ dibagi menjadi 9 department yang dibedakan berdasarkan berdasarkan fungsi dan peran dalam department tersebut. Pembagian department dalam PT XYZ adalah sebagai berikut: Sales (SLS), Marketing (MKT), Technical Support (SUP), Supply Chain Management (SCM), Operations (OPS), Human Resources 
Management (HRM), Finance Accounting Tax (FAT), Information Technology (ITO), dan Quality Management System (QMS).

Dalam pelaksanaan Visi dan Misi perusahaan, PT XYZ melakukan pembuatan strategi bisnis jangka panjang yang biasanya akan di evaluasi setiap 3 tahun sekali. Strategi bisnis perusahaan ini biasanya akan dibuat dengan melihat semua aspek dalam Balanced Scorecard yaitu : Keuangan, Pelanggan, Proses Bisnis Internal, serta Pembelajaran Dan Pertumbuhan.

Dalam menjalankan bisnisnya PT XYZ sangat mengandalkan sumber daya manusia untuk dapat mengembangkan bisnis dan mencapai target sales yang telah ditetapkan. Dalam hal ini peran Department Human Resources Development sangat besar, baik dalam perekrutan karyawan yang berkualitas serta pengembangan kompetensi karyawan agar karyawan dapat mencapai target yang ditetapkan perusahaan. Selain itu Department Human Resources Management juga bertanggung jawab terhadap pelaksanaan kebijakan perusahaan dalam pelaksanaan penilaian kinerja karyawan setiap 6 bulan sekali, yang bertujuan melihat kinerja masing-masing karyawan.

\section{Analisis Balanced Scorecard Pada Department Human Resources Management PT XYZ Tahap I: Pembuatan Visi Misi}

Pembuatan strategi perusahaan dimulai dengan pembuatan Visi Misi Perusahaan. Karena dalam artikel ini akan dibahas penerapan balanced scorecard pada Department Human Resources Management, maka akan langsung dibahas visi misi dari Department Human Resources Management, yang merupakan penjabaran visi misi perusahaan yang sudah disesuaikan dengan peran Department Human Resources Management. Berikut ini merupakan Visi Misi Department Human Resources Management pada PT XYZ:

Visi: Menjadi business partner bagi setiap department dalam mengelola dan mengembangkan sumber daya manusia dalam rangka mendukung pencapaian tujuan perusahaan.

\section{Misi:}

1. Melakukan pengelolaan sumber daya manusia dengan baik.

2. Melakukan pengembangan sumber daya manusia sesuai dengan kompetensi yang dibutuhkan oleh perusahaan.

3. Membangun budaya perusahaan yang positif sesuai nilai-nilai budaya perusahaan.

\section{Tahap II: Pembuatan Tujuan}

Pada tahap ke 2 ini, pembuatan tujuan Department Human Resources Management dilakukan dengan menjabarkan visi misi department menjadi sebuah tujuan yang ingin dicapai oleh Department Human Resources Mangement. Dalam hal ini tujuan yang ingin dicapai oleh Department Human Resources Mangement adalah untuk menjadi bekerja sama dengan semua department dalam pengelolaan dan pengembangan sumber daya manusia sesuai kompetensi yang dibutuhkan oleh perusahaan.

\section{Tahap III: Pembuatan Peta Strategi}

Dengan berdasarkan pada peta strategi perusahaan, maka strategi pada masing - masing Department dapat disusun. Penyusunan strategi pada masing-masing department tentunya disesuaikan dengan fungsi dan peran department tersebut dalam perusahaan. Berikut ini merupakan peta strategi Department Human Resources Management yang dibuat dengan menggunakan 4 perspektif Balanced Scorecard, sbb: 


\section{HUMAN RESOURCES MANAGEMENT STRATEGY MAP}

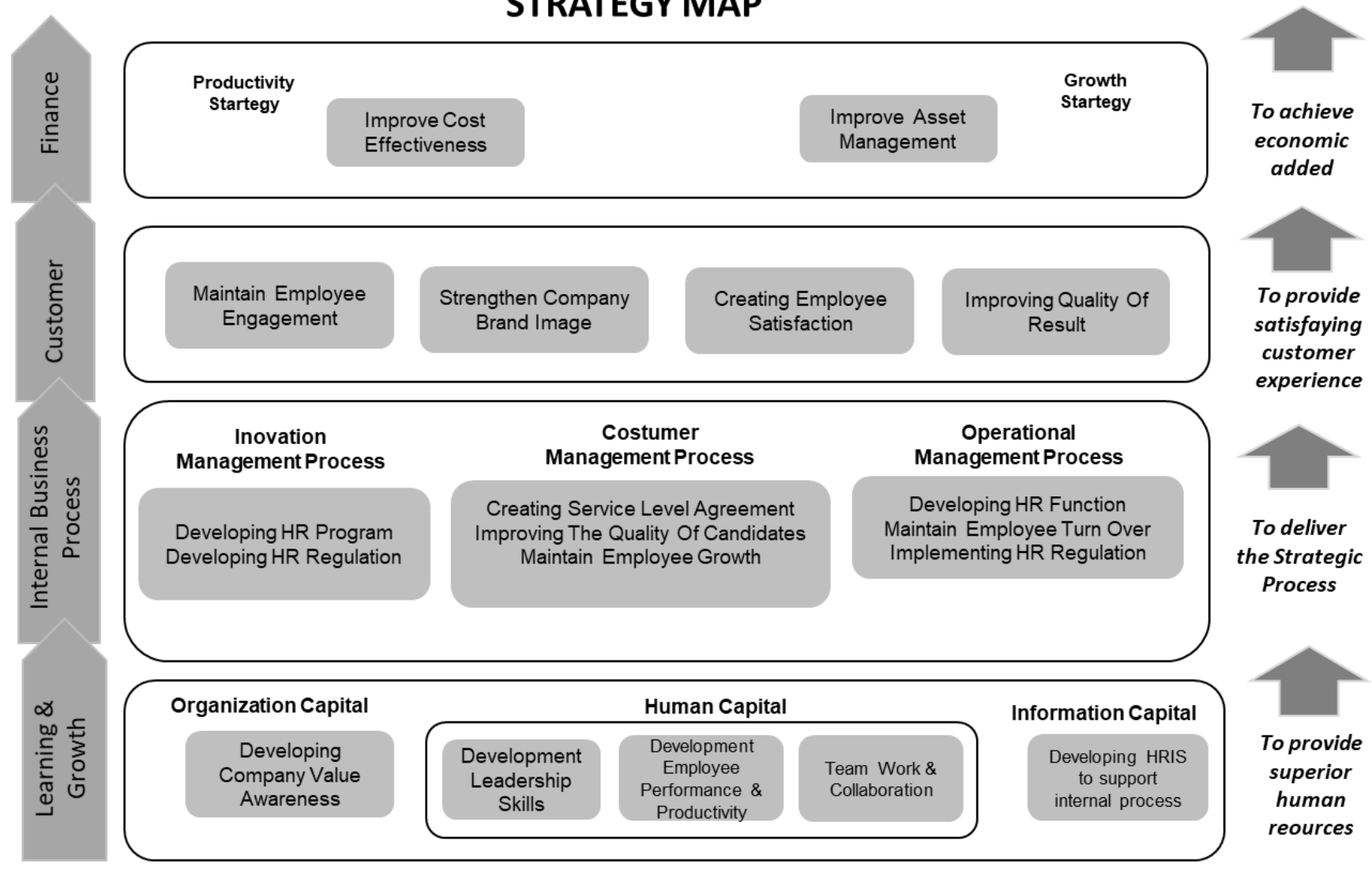

Setelah Peta Strategi Department Human Resources Development dibuat maka selanjutnya dapat dilakukan pembuatan persepktif Balanced Scorecard dengan tahapan sbb:

\section{Tahap IV: Pembuatan Bobot}

Pada Tahap IV ini pembuatan bobot pada masing-masing perseptif Balanced Scorecard dilakukan dengan melihat tingkat kesulitan pencapaian serta derajat kepentingan masing-masing perspektif dalam Balanced Scorecard terhadap kegiatan Department Human Resources Management. Dengan melihat tingkat kesulitan dalam pencapaian kegiatan strategi serta derajat kepentingan kegiatan strategi terhadap pencapaian tujuan, maka berikut ini merupakan bobot dalam setiap perspektif pada department Human Resources Management:

- Keuangan: $15 \%$

- Pelanggan: $20 \%$

- Proses Bisnis Internal: $20 \%$

- Pembelajaran \& Pertumbuhan: $45 \%$

Bobot terbesar ada pada persektif Pembelajaran \& Pertumbuhan karena terkait dengan fungsi dari Department Human Resources Management sebagai Business Partner yang bertugas mengelola dan mengembangkan sumber daya manusia, maka derajat kepentingan yang paling besar ada pada persektif tersebut. 


\section{Tahap V: Pembuatan Sasaran Strategis}

Pembuatan Sasaran Strategis dalam Department Human Resources Management didasarkan pada peta strategi perusahaan. Dalam hal ini sasaran strategis harus dilakukan dengan melihat proses dan kegiatan dalam Department Human Resources Management, sehingga sasaran strategi tersebut dapat dijabarkan menjadi suatu indikator kerja. Berikut ini adalah sasaran strategis yang ditentukan dalam Department Human Reources:

- Keuangan:

Improve Cost Effectiveness: sasaran strategis ini ditujukan untuk melakukan efisiensi terhadap biaya sumber manusia yang dibutuhkan perusahaan.

Improve Financial Statement: sasaran strategis ini ditujukan untuk meningkatkan keseimbangan dalam laporan keuangan.

- Pelanggan:

Engage \& Increase Loyal Customer: sasaran strategis ini ditujukan untuk meningkatkan ikatan dengan konsumen, dalam hal ini yang dimaksud konsumen adalah karyawan.

- Proses Bisnis Internal:

Quality Commitment: sasaran strategis ini ditujukan untuk meningkatkan kualitas komitmen dan fungsi dalam department.

- Pembelajaran \& Pertumbuhan:

Organization Capital: sasaran strategis ini ditujukan untuk menggambarkan pembelajaran dan pertumbuhan dalam organisasi.

Human Capital: sasaran strategis ini ditujukan untuk menggambarkan pembelajaran dan pertumbuhan dari sumber daya manusia.

\section{Tahap VI: Pembuatan Indikator Kerja Utama}

Indikator Utama Kerja dibuat pada persepktif Balanced Scorecard dengan mengacu pada Sasaran Strategi yang telah ditetapkan. Tentunya IndIkator Kerja Utama ini harus disesuaikan dengan tujuan yang ingin dicapai pada masing - masing sasaran strategis.

- Keuangan:

Budget \& Control: indikator kerja utama ini bertujuan sebagai pengawasan terkait dengan budget dan realisasi yang dilakukan.

Company Asset Utilization - Internal: indikator kerja utama ini bertujuan sebagai pengawasan terhadap penggunaan aset perusahaan.

- Pelanggan:

CLI (Customer Loyality Index) \& CSI (Customer Satisfaction Index): indikator kerja utama ini bertujuan sebagai pengawasan terhadap index loyalitas karyawan serta index kepuasan karyawan.

- Proses Bisnis Internal:

Quality Commitment: indikator kerja utama ini bertujuan sebagai pengawasan terhadap kegiatan bisnis interla yang dilakukan Department Human Resources Management.

- Pembelajaran \& Pertumbuhan:

Culture: indikator kerja utama ini bertujuan sebagai pengawasan terhadap pembentukan budaya positif didalam perusahaan.

Engage \& Competence Employee: indikator kerja utama ini bertujuan sebagai pengawasan terhadap proses pembelajaran dan pertumbuhan karyawan. 


\section{Tahap VII : Pembuatan Target Kerja}

Tahap pembuatan target kerja ini merupakan penjabaran Indikator Kerja Utama menjadi sebuah target kerja yang merupakan aktifitas yang dilakukan untuk mencapai Indikator Kerja Utama yang telah ditentukan.

Berikut ini adalah target kerja Department Human Resources Mangement, sbb:

- Keuangan: Pengendalian Budget HRGA, Manajemen Aset Perusahaan.

- Pelanggan: Pelaksanaan Employers of Choice (EOC) Survey, SLA HR Operations, SLA HR Recruitment Level Spv \& Up, SLA General Affairs.

- Proses Bisnis Internal: Monthly Report, Maintain employee turnover, Jobfair, Penyelesaian temuan internal/eksternal audit.

- Pembelajaran \& Pertumbuhan: Company Value Campaign, Pelaksanaan Training Plan, New Employee Orientation, Pelaksanaan Performance Appraisal (PA), serta Coaching, Project, Assigment.

\section{Tahap VIII: Target}

Pada tahap VIII ini, pembuatan target biasanya dilakukan berdasarkan dengan target yang diharapkan oleh perusahaan. Target yang diberikan harus dapat diukur secara kuantitatif sehingga memudahkan dalam perhitungan pencapaian kinerja pada masing-masing target kerja.

Beberapa target ditetapkan berdasarkan pada data historikal misalkan target pada turnover karyawan, pada tahun 2019 target turnover ditetapkan maksimum sebesar 18\%. Target sebesar 18\% ditetapkan berdasarkan data Turn Over karyawan pada tahun 2018, sehingga pada tahun 2019 diharapkan nilai turn over tidak lebih besar dari $18 \%$.

Selain itu bisa berdasarkan kondisi internal perusahaan, misalkan pada penetapan Service Level Agreement pada HR Operations, HR Recruitment serta SLA pada General Affairs. Dengan melihat kepada kondisi internal perusahaan dimana faktor geografis dari masing-masing representative office yang tersebar di seluruh Indonesia, maka Service Level Agreement pada HR Operations serta General Affairs dibuat 14 hari kerja, diasumsikan dengan penetapan 14 hari kerja, proses administrasi dan proses pemenuhan dapat dilakukan dengan baik. Sedangkan untuk SLA Recruitment level Supervisor \& Up ditetapkan selama 60 hari kerja dengan asumsi bahwa pencarian untuk kandidat karyawan pada level ini membutuhkan waktu yang cukup panjang.

Selain itu penentuan target juga bisa berdasarkan pada penetapan target yang tetap setiap tahunnya, misalkan pada target kerja Pengendalian Budget HRGA serta Pelaksanaan Employers Of Choice (EOC) Survey. Hal ini dapat ditetapkan berdasarkan keputusan dari perusahaan ataupun berdasarkan penetapan rumus pada masing - masing target kerja.

Perspektif Keuangan:

\begin{tabular}{|c|c|c|c|c|c|c|c|c|}
\hline No & Perspektif & $\begin{array}{l}\text { Sasaran } \\
\text { Strategis }\end{array}$ & Indikator Kerja Utama & Target Kerja & Rumus & Satuan & Target & Bobot \\
\hline \multirow{2}{*}{1} & \multirow{2}{*}{ Keuangan } & $\begin{array}{l}\text { Improve Cost } \\
\text { Effectiveness }\end{array}$ & Budget \& Control & $\begin{array}{l}\text { Pengendalian Budget } \\
\text { HRGA }\end{array}$ & $\begin{array}{l}(\text { Total Realisasi/Total } \\
\text { Budget) }{ }^{*} 100 \%\end{array}$ & $\%$ & \begin{tabular}{|l} 
Penggunaan Budget < sales \\
achievement $100 \%$. Penggunaan \\
Budget > sales achievement $=0 \%$
\end{tabular} & $10 \%$ \\
\hline & & $\begin{array}{l}\text { Improve } \\
\text { Financial } \\
\text { Statement }\end{array}$ & Company Asset Utilization & $\begin{array}{l}\text { Manajemen Aset } \\
\text { Perusahaan }\end{array}$ & $\begin{array}{l}\text { (Aset Kondisi } \\
\text { Baik/Total Aset } \\
\text { Tercatat) }{ }^{*} 100 \%\end{array}$ & $\%$ & Aset kondisi baik $=100 \%$ & $5 \%$ \\
\hline
\end{tabular}


Perspektif Pelanggan:

\begin{tabular}{|c|c|c|c|c|c|c|c|c|}
\hline No & Perspektif & $\begin{array}{l}\text { Sasaran } \\
\text { Strategis }\end{array}$ & Indikator Kerja Utama & Target Kerja & Rumus & Satuan & Target & Bobot \\
\hline \multirow{4}{*}{2} & \multirow{4}{*}{ Pelanggan } & \multirow{4}{*}{$\begin{array}{l}\text { Engage \& } \\
\text { Increase Loyal } \\
\text { Customer }\end{array}$} & \multirow{4}{*}{ CLI \& CSI } & $\begin{array}{l}\text { Pelaksanaan Employers } \\
\text { Of Choice (EOC) Survey }\end{array}$ & $\begin{array}{l}\text { (pelaksanaan survey } \\
\text { setahun } / 1)^{\star} 100 \%\end{array}$ & $\%$ & $\begin{array}{l}1 \text { kali setahun }=100 \% \\
\text { tidak dilakukan }=0 \%\end{array}$ & $5 \%$ \\
\hline & & & & SLA HR Operations & $\begin{array}{l}\text { (rata-rata } \\
\text { SLA/standard } \\
\text { SLA }{ }^{\star} 100 \%\end{array}$ & $\%$ & $\begin{array}{l}\text { SLA HR Operations } \leq 14 \mathrm{HK} \\
=100 \%\end{array}$ & $5 \%$ \\
\hline & & & & $\begin{array}{l}\text { SLA HR Recruitment Level } \\
\text { Spv \& Up }\end{array}$ & $\begin{array}{l}\text { (rata-rata } \\
\text { SLA/standard } \\
\text { SLA) }{ }^{\star} 100 \%\end{array}$ & $\%$ & $\begin{array}{l}\text { Max } 60 \text { hari. SLA HR Rec } \\
\text { Mgr \& Up } \leq 100 \%\end{array}$ & $5 \%$ \\
\hline & & & & SLA GA & $\begin{array}{l}\text { (rata-rata } \\
\text { SLA/standard } \\
\text { SLA })^{*} 100 \%\end{array}$ & $\%$ & SLA GA $\leq 14 \mathrm{HK}=100 \%$ & $5 \%$ \\
\hline
\end{tabular}

Perspektif Proses Bisnis Internal :

\begin{tabular}{|c|c|c|c|c|c|c|c|c|}
\hline No & Perspektif & $\begin{array}{l}\text { Sasaran } \\
\text { Strategis }\end{array}$ & Indikator Kerja Utama & Target Kerja & Rumus & Satuan & Target & Bobot \\
\hline \multirow{4}{*}{3} & \multirow{4}{*}{$\begin{array}{l}\text { Proses Bisnis } \\
\text { Internal }\end{array}$} & \multirow{4}{*}{$\begin{array}{c}\text { Quality } \\
\text { Commitment }\end{array}$} & \multirow{4}{*}{ Quality Commitment } & Monthly Report & \begin{tabular}{|l} 
(Jumlah report \\
ontime/jumlah target \\
report yang harus
\end{tabular} & $\%$ & $\begin{array}{l}\text { HK ke- } 5 \text { setiap bulan }= \\
100 \%, \text { HK ke- } 6=0 \%\end{array}$ & $5 \%$ \\
\hline & & & & $\begin{array}{l}\text { Maintain employee } \\
\text { turnover }\end{array}$ & $\begin{array}{l}\text { (Jumlah karyawan } \\
\text { resign/Total } \\
\text { karyawan)*100\% }\end{array}$ & $\%$ & $\begin{array}{l}\text { TO } \leq 10 \%=100 \%, 10>X \leq \\
18 \%=75 \%,>18 \%=0 \%\end{array}$ & $5 \%$ \\
\hline & & & & Jobfair & $\begin{array}{l}\text { (Jumlah kegiatan } \\
\text { jobfair/Target jobfair } \\
\text { setahun) }{ }^{\star} 100 \%\end{array}$ & $\%$ & Kegiatan $\geq 2=100 \%$ & $5 \%$ \\
\hline & & & & $\begin{array}{l}\text { Penyelesaian temuan } \\
\text { internal/eksternal audit }\end{array}$ & $\begin{array}{l}\text { Sebelum target waktu } \\
=120 \% ; \\
\text { Ontime }=100 \%\end{array}$ & $\%$ & $100 \%$ ontime & $5 \%$ \\
\hline
\end{tabular}

Perspektif Pembelajaran dan Pertumbuhan :

\begin{tabular}{|c|c|c|c|c|c|c|c|c|}
\hline No & Perspektif & $\begin{array}{l}\text { Sasaran } \\
\text { Strategis }\end{array}$ & Indikator Kerja Utama & Target Kerja & Rumus & Satuan & Target & Bobot \\
\hline \multirow{5}{*}{4} & \multirow{5}{*}{$\begin{array}{l}\text { Pembelajaran \& } \\
\text { Pertumbuhan }\end{array}$} & $\begin{array}{l}\text { Organization } \\
\text { Capital }\end{array}$ & Culture & Company Value Campaign & $\begin{array}{l}\text { (Jumlah kegiatan/ } \\
\text { Target kegiatan) }{ }^{*} 100 \%\end{array}$ & $\%$ & $\begin{array}{l}\text { Kegiatan sesuai target = } \\
100 \%\end{array}$ & $5 \%$ \\
\hline & & \multirow{4}{*}{ Human Capital } & \multirow{4}{*}{$\begin{array}{l}\text { Engage \& Competence } \\
\text { Employee }\end{array}$} & Pelaksanaan Training Plan & $\begin{array}{l}\text { (Jumlah kegiatan/ } \\
\text { Target kegiatan) }{ }^{*} 100 \%\end{array}$ & $\%$ & $\begin{array}{l}\text { Kegiatan sesuai target = } \\
100 \%\end{array}$ & $10 \%$ \\
\hline & & & & New Employee Orientation & $\begin{array}{l}\text { (Jumlah kegiatan/ } \\
\text { Target kegiatan) }{ }^{\star} 100 \%\end{array}$ & $\%$ & Setiap 3 bulan & $10 \%$ \\
\hline & & & & $\begin{array}{l}\text { Pelaksanaan Performance } \\
\text { Appraisal (PA) }\end{array}$ & $\begin{array}{l}\text { (Jumlah kegiatan/ } \\
\text { target kegiatan) }{ }^{\star} 100 \%\end{array}$ & $\%$ & Januari 2019 \& Juli 2019 & $10 \%$ \\
\hline & & & & $\begin{array}{l}\text { Coaching, Project, } \\
\text { Assigment }\end{array}$ & $\begin{array}{l}\text { (Jumlah kegiatan/ } \\
\text { Target kegiatan)* } 100 \%\end{array}$ & $\%$ & $\begin{array}{l}\text { Kegiatan sesuai target }= \\
100 \%\end{array}$ & $10 \%$ \\
\hline
\end{tabular}

\section{Tahap IX : Realisasi}

Pada tahap IX ini realisasi dilakukan dengan melakukan perhitungan pada setiap target kerja dengan menggunakan rumus maupun perhitungan yang telah ditentukan. Berikut ini merupakan penjabaran realisasi yang telah dilakukan pada penilaian kinerja Department Human Resources Management pada tahun 2019 : 


\begin{tabular}{|c|c|c|c|c|c|c|c|c|c|}
\hline No & Perspektif & $\begin{array}{l}\text { Sasaran } \\
\text { Strategis }\end{array}$ & Indikator Kerja Utama & Target Kerja & Rumus & Satuan & Target & Bobot & Realisasi \\
\hline \multirow{2}{*}{1} & \multirow{2}{*}{ Keuangan } & $\begin{array}{l}\text { Improve Cost } \\
\text { Effectiveness }\end{array}$ & Budget \& Control & $\begin{array}{l}\text { Pengendalian Budget } \\
\text { HRGA }\end{array}$ & $\begin{array}{l}\text { (Total Realisasi/Total } \\
\text { Budget })^{*} 100 \%\end{array}$ & $\%$ & $\begin{array}{l}\text { Penggunaan Budget }<\text { sales } \\
\text { achievement } 100 \% \text {. Penggunaan } \\
\text { Budget }>\text { sales achievement }=0 \%\end{array}$ & $10 \%$ & $9,48 \%$ \\
\hline & & \begin{tabular}{|l|} 
Improve \\
Financial \\
Statement \\
\end{tabular} & Company Asset Utilization & $\begin{array}{l}\text { Manajemen Aset } \\
\text { Perusahaan }\end{array}$ & \begin{tabular}{|l|} 
(Aset Kondisi \\
Baik/Total Aset \\
Tercatat)**100\% \\
\end{tabular} & $\%$ & Aset kondisi baik $=100 \%$ & $5 \%$ & $4,94 \%$ \\
\hline \multirow{4}{*}{2} & \multirow{4}{*}{ Pelanggan } & \multirow{4}{*}{$\begin{array}{l}\text { Engage \& } \\
\text { Increase Loyal } \\
\text { Customer }\end{array}$} & \multirow{4}{*}{ CLI \& CSI } & $\begin{array}{l}\text { Pelaksanaan Employers } \\
\text { Of Choice (EOC) Survey }\end{array}$ & $\begin{array}{l}\text { (pelaksanaan survey } \\
\text { setahun/1)*100\% }\end{array}$ & $\%$ & $\begin{array}{l}1 \text { kali setahun }=100 \% \\
\text { tidak dilakukan }=0 \%\end{array}$ & $5 \%$ & $5 \%$ \\
\hline & & & & SLA HR Operations & $\begin{array}{l}\text { (rata-rata } \\
\text { SLA/standard } \\
\text { SLA })^{*} 100 \% \\
\end{array}$ & $\%$ & $\begin{array}{l}\text { SLA HR Operations } \leq 14 \mathrm{HK} \\
=100 \%\end{array}$ & $5 \%$ & $4,64 \%$ \\
\hline & & & & $\begin{array}{l}\text { SLA HR Recruitment Level } \\
\text { Spv \& Up }\end{array}$ & $\begin{array}{l}\text { (rata-rata } \\
\text { SLA/standard } \\
\text { SLA })^{*} 100 \%\end{array}$ & $\%$ & $\begin{array}{l}\text { Max } 60 \text { hari. SLA HR Rec } \\
\text { Mgr \& Up } \leq 100 \%\end{array}$ & $5 \%$ & $4,67 \%$ \\
\hline & & & & SLA GA & $\begin{array}{l}\text { rata-rata } \\
\text { SLA/standard } \\
\text { SLA)* } 100 \% \\
\end{array}$ & $\%$ & SLA GA $\leq 14 \mathrm{HK}=100 \%$ & $5 \%$ & $4,50 \%$ \\
\hline \multirow{4}{*}{3} & \multirow{4}{*}{$\begin{array}{l}\text { Proses Bisnis } \\
\text { Internal }\end{array}$} & \multirow{4}{*}{$\begin{array}{l}\text { Quality } \\
\text { Commitment }\end{array}$} & \multirow{4}{*}{ Quality Commitment } & Monthly Report & $\begin{array}{l}\text { (Jumlah report } \\
\text { ontime/jumlah target } \\
\text { report yang harus }\end{array}$ & $\%$ & $\begin{array}{l}\text { HK ke- } 5 \text { setiap bulan }= \\
100 \%, \text { HK ke- } 6=0 \%\end{array}$ & $5 \%$ & $5,00 \%$ \\
\hline & & & & $\begin{array}{l}\text { Maintain employee } \\
\text { turnover }\end{array}$ & $\begin{array}{l}\text { (Jumlah karyawan } \\
\text { resign/Total } \\
\text { karyawan)* } 100 \% \\
\end{array}$ & $\%$ & $\begin{array}{l}\text { TO } \leq 10 \%=100 \%, 10>\mathrm{X} \leq \\
18 \%=75 \%,>18 \%=0 \%\end{array}$ & $5 \%$ & $3,75 \%$ \\
\hline & & & & Jobfair & $\begin{array}{l}\text { (Jumlah kegiatan } \\
\text { jobfair/Target jobfair } \\
\text { setahun)* } 100 \% \\
\end{array}$ & $\%$ & Kegiatan $\geq 2=100 \%$ & $5 \%$ & $5,00 \%$ \\
\hline & & & & $\begin{array}{l}\text { Penyelesaian temuan } \\
\text { internal/eksternal audit }\end{array}$ & $\begin{array}{l}\text { Sebelum target waktu } \\
=120 \% \text {; } \\
\text { Ontime }=100 \% \text {; }\end{array}$ & $\%$ & $100 \%$ ontime & $5 \%$ & $5,00 \%$ \\
\hline \multirow{5}{*}{4} & \multirow{5}{*}{$\begin{array}{l}\text { Pembelajaran \& } \\
\text { Pertumbuhan }\end{array}$} & $\begin{array}{l}\text { Organization } \\
\text { Capital }\end{array}$ & Culture & Company Value Campaign & $\mid \begin{array}{l}\text { (Jumlah kegiatan/ } \\
\text { Target kegiatan) }{ }^{*} 100 \%\end{array}$ & $\%$ & $\begin{array}{l}\text { Kegiatan sesuai target }= \\
100 \%\end{array}$ & $5 \%$ & $3,50 \%$ \\
\hline & & \multirow{4}{*}{ Human Capital } & \multirow{4}{*}{$\begin{array}{l}\text { Engage \& Competence } \\
\text { Employee }\end{array}$} & Pelaksanaan Training Plan & $\begin{array}{l}\text { (Jumlah kegiatan/ } \\
\text { Target kegiatan) }{ }^{\star} 100 \%\end{array}$ & $\%$ & $\begin{array}{l}\text { Kegiatan sesuai target }= \\
100 \%\end{array}$ & $10 \%$ & $7,33 \%$ \\
\hline & & & & New Employee Orientation & $\begin{array}{l}\text { (Jumlah kegiatan/ } \\
\text { Target kegiatan) }{ }^{*} 100 \%\end{array}$ & $\%$ & Setiap 3 bulan & $10 \%$ & $10 \%$ \\
\hline & & & & $\begin{array}{l}\text { Pelaksanaan Performance } \\
\text { Appraisal (PA) }\end{array}$ & \begin{tabular}{|l|}
$($ Jumlah kegiatan/ \\
target kegiatan)*
\end{tabular} & $\%$ & Januari 2019 \& Juli 2019 & $10 \%$ & $10 \%$ \\
\hline & & & & $\begin{array}{l}\text { Coaching, Project, } \\
\text { Assigment }\end{array}$ & $\begin{array}{l}\text { (Jumlah kegiatan/ } \\
\text { Target kegiatan) }{ }^{*} 100 \%\end{array}$ & $\%$ & $\begin{array}{l}\text { Kegiatan sesuai target = } \\
100 \%\end{array}$ & $10 \%$ & $5 \%$ \\
\hline \multicolumn{8}{|c|}{ Total } & $100 \%$ & $87,81 \%$ \\
\hline
\end{tabular}

Contoh realisasi pada Sasaran Strategis Improve Financial Statement dengan target kerja Manajemen Aset Perusahaan dapat dihitung dengan menggunakan rumus :

Manajemen Aset Perusahaan $=\frac{\text { Aset Kondisi Baik }}{\text { Total Aset Tercatat }} \times 100 \%$

Dengan menggunakan data aset yang sudah diperiksa, yaitu aset dalam kondisi baik sebanyak 1524 aset, dari total aset yang dimiliki sebanyak 1542 aset. Maka perumusan Manajemen aset perusahaan dapat dihitung sbb :

Manajemen Aset Perusahaan $=\frac{1524}{1542} \times 100 \%=98,83 \%$ artinya aset perusahaan yang ada dalam kondisi baik sebanyak 98,93\%.

Karena dalam masing - masing target kerja telah ditentukan bobot sesuai tingkat kesulitan pencapaian atau sesuai dengan derajat kepentingan, maka hasil perhitungan pada setiap target kerja akan dikalikan dengan bobot yang ada, sbb :

Manajemen Aset Perusahaan $=\frac{1524}{1542} \times 100 \% \times 5 \%=4,94 \%$ 
Setelah semua target kerja diperhitungkan dengan menggunakan rumus yang ada serta dikalikan dengan bobot pada masing-masing target kerja, akan dihasilkan total realisasi dari semua target kerja yang ada.

Dalam tabel diatas dapat total realisasi dari semua target kerja adalah $87,81 \%$ dari total pencapaian yang diharapkan sebesar $100 \%$. Hal ini disebabkan karena adanya beberapa target kerja yang tidak bisa tercapai selama tahun 2019.

\section{Tahap X : Scor Dalam Balanced Scorecard}

Dalam tahap ini dilakukan perbandingan antara target serta realisasi untuk mengetahui target kerja yang tidak tercapai. Pada tahap ini pencapaian dikategorikan menjadi 3 kategori, yaitu sbb :

- Kategori Hijau : Pencapaian 76\% - 100\% diberikan warna hijau, dalam kategori ini pencapaian masih dalam batas toleransi.

- Kategori Kuning : Pencapaian 50 - >75\% diberikan warna kuning, dalam kategori ini pencapaian harus dievaluasi apakah ada kendala dalam pelaksanaan target kerja.

- Kategori Merah : Pencapaian < 50\% diberikan warna merah, dalam kategori ini pencapaian harus dievaluasi dan dimonitoring dengan teliti apakah ada target kerja yang tidak dilakukan.

Dalam tahap X ini dapat dilakukan analisa terkait hasil realisasi dari masing-masing target kerja yang masih belum tercapai secara optimal serta dapat dilakukan analisa terkait total pencapaian semua target kerja yang telah ditetapkan. Pada kolom pencapaian 2019, dapat dilihat perbandingan target serta hasil realisasi pada masing-masing target kerja. Sehingga nilai pencapaian yang muncul akan menggambarkan prosentase pencapaian pada setiap target pada tahun 2019, dan menjadi dasar untuk melakukan analisa target kerja yang dapat tercapai dengan baik serta target kerja yang belum berhasil dicapai dengan baik.

\begin{tabular}{|c|c|c|c|c|c|c|c|c|c|c|c|}
\hline No & Perspektif & $\begin{array}{l}\text { Sasaran } \\
\text { Strategis }\end{array}$ & Indikator Kerja Utama & Target Kerja & Rumus & Satuan & Target & Bobot & Realisasi & Keterangan & $\begin{array}{l}\text { Pencapaian } \\
\quad 2019\end{array}$ \\
\hline \multirow{2}{*}{1} & \multirow{2}{*}{ Keuangan } & $\begin{array}{l}\text { Improve Cost } \\
\text { Effectiveness }\end{array}$ & Budget \& Control & $\begin{array}{l}\text { Pengendalian Budget } \\
\text { HRGA }\end{array}$ & $\begin{array}{l}\text { (Total Realisasi/Total } \\
\text { Budget) }{ }^{*} 100 \%\end{array}$ & $\%$ & \begin{tabular}{|l} 
Penggunaan Budget < sales \\
achievement 100\%. Penggunaan \\
Budget $>$ sales achievement $=0 \%$
\end{tabular} & $10 \%$ & $9,48 \%$ & \begin{tabular}{|l|} 
Target \\
Realisasi \\
Pencapaian \\
\end{tabular} & \begin{tabular}{|l|}
$10,00 \%$ \\
$9,48 \%$ \\
$94,78 \%$ \\
\end{tabular} \\
\hline & & \begin{tabular}{|l|} 
Improve \\
Financial \\
Statement
\end{tabular} & Company Asset Utilization & $\begin{array}{l}\text { Manajemen Aset } \\
\text { Perusahaan }\end{array}$ & \begin{tabular}{|l|} 
Aset Kondisi \\
Baik/Total Aset \\
Tercatat)*100\%
\end{tabular} & $\%$ & Aset kondisi baik $=100 \%$ & $5 \%$ & $4,94 \% \frac{T}{F}$ & \begin{tabular}{|l|} 
Target \\
Realisasi \\
Pencapaian \\
\end{tabular} & \begin{tabular}{|l|}
$5,00 \%$ \\
$4,94 \%$ \\
$98,83 \%$ \\
\end{tabular} \\
\hline \multirow{4}{*}{2} & \multirow{4}{*}{ Pelanggan } & \multirow{4}{*}{$\begin{array}{l}\text { Engage \& } \\
\text { Increase Loyal } \\
\text { Customer }\end{array}$} & \multirow{4}{*}{ CLI \& CSI } & $\begin{array}{l}\text { Pelaksanaan Employers } \\
\text { Of Choice (EOC) Survey }\end{array}$ & $\begin{array}{l}\text { (pelaksanaan survey } \\
\text { setahun } / 1)^{*} 100 \%\end{array}$ & $\%$ & $\begin{array}{l}1 \text { kali setahun }=100 \% \\
\text { tidak dilakukan }=0 \%\end{array}$ & $5 \%$ & $5 \%$ & \begin{tabular}{|l|} 
Target \\
Realisasi \\
Pencapaian \\
\end{tabular} & $\begin{array}{c}5,00 \% \\
5,00 \% \\
100,00 \% \\
\end{array}$ \\
\hline & & & & SLA HR Operations & $\begin{array}{l}\text { (rata-rata } \\
\text { SLA/standard } \\
\text { SLA)*100\% }\end{array}$ & $\%$ & $\begin{array}{l}\text { SLA HR Operations } \leq 14 \mathrm{HK} \\
=100 \%\end{array}$ & $5 \%$ & $4,64 \%$ & \begin{tabular}{|l|} 
Target \\
Realisasi \\
Pencapaian \\
\end{tabular} & $\begin{array}{l}5,00 \% \\
4,64 \% \\
92,75 \% \\
\end{array}$ \\
\hline & & & & $\begin{array}{l}\text { SLA HR Recruitment Level } \\
\text { Spv \& Up }\end{array}$ & $\begin{array}{l}\text { (rata-rata } \\
\text { SLA/standard } \\
\text { SLA)*100\% }\end{array}$ & $\%$ & $\begin{array}{l}\text { Max } 60 \text { hari. SLA HR Rec } \\
\text { Mgr \& Up } \leq 100 \%\end{array}$ & $5 \%$ & $4,67 \%$ & \begin{tabular}{|l|} 
Target \\
Realisasi \\
Pencapaian \\
\end{tabular} & \begin{tabular}{|l|}
$5,00 \%$ \\
$4,67 \%$ \\
$93,42 \%$ \\
\end{tabular} \\
\hline & & & & SLA GA & $\begin{array}{l}\text { (rata-rata } \\
\text { SLA/standard } \\
\text { SLA)* } 100 \% \\
\end{array}$ & $\%$ & SLA GA $\leq 14 \mathrm{HK}=100 \%$ & $5 \%$ & $4,50 \%$ & \begin{tabular}{|l|} 
Target \\
Realisasi \\
Pencapaian \\
\end{tabular} & \begin{tabular}{|l|}
$5,00 \%$ \\
$4,50 \%$ \\
$90,00 \%$ \\
\end{tabular} \\
\hline & & & & Monthly Report & \begin{tabular}{|l|} 
(Jumlah report \\
ontime/jumlah target \\
report yang harus
\end{tabular} & $\%$ & $\begin{array}{l}\text { HK ke- } 5 \text { setiap bulan }= \\
100 \%, \text { HK ke- } 6=0 \%\end{array}$ & $5 \%$ & \begin{tabular}{l|l}
\multirow{2}{*}{$5,00 \%$} & $\frac{T}{1}$ \\
\cline { 2 - 2 } & $F$ \\
\end{tabular} & \begin{tabular}{|l|} 
Target \\
Realisasi \\
Pencapaian \\
\end{tabular} & $\begin{array}{c}5,00 \% \\
5,00 \% \\
100,00 \% \\
\end{array}$ \\
\hline 3 & Proses Bisnis & Quality & & $\begin{array}{l}\text { Maintain employee } \\
\text { turnover }\end{array}$ & \begin{tabular}{|l|}
$\begin{array}{l}\text { (Jumlah karyawan } \\
\text { resign/Total } \\
\text { karyawan)*100\% }\end{array}$ \\
\end{tabular} & $\%$ & $\begin{array}{l}\text { TO } \leq 10 \%=100 \%, 10>X \leq \\
18 \%=75 \%,>18 \%=0 \%\end{array}$ & $5 \%$ & $3,75 \% \frac{T}{F}$ & \begin{tabular}{|l|} 
Target \\
Realisasi \\
Pencapaian \\
\end{tabular} & $\begin{array}{l}5,00 \% \\
3,75 \% \\
75,00 \% \\
\end{array}$ \\
\hline 3 & Internal & Commitment & Quality Commitment & Jobfair & \begin{tabular}{|l} 
(Jumlah kegiatan \\
jobfair/Target jobfair \\
setahun)*100\%
\end{tabular} & $\%$ & Kegiatan $\geq 2=100 \%$ & $5 \%$ & $5,00 \% \frac{T}{\frac{F}{F}}$ & \begin{tabular}{|l|} 
Target \\
Realisasi \\
Pencapaian \\
\end{tabular} & $\begin{array}{c}5,00 \% \\
5,00 \% \\
100,00 \% \\
\end{array}$ \\
\hline & & & & \begin{tabular}{|l} 
Penyelesaian temuan \\
internal/eksternal audit
\end{tabular} & $\begin{array}{l}\text { Sebelum target waktu } \\
=120 \% \text {; } \\
\text { Ontime = } 100 \% \text {; }\end{array}$ & $\%$ & $100 \%$ ontime & $5 \%$ & \begin{tabular}{l|l}
\multirow{2}{*}{$5,00 \%$} & $\frac{T}{F}$ \\
\cline { 2 - 2 } & $F$ \\
\end{tabular} & \begin{tabular}{|l|} 
Target \\
Realisasi \\
Pencapaian \\
\end{tabular} & $\begin{array}{c}5,00 \% \\
5,00 \% \\
100,00 \% \\
\end{array}$ \\
\hline & & $\begin{array}{l}\text { Organization } \\
\text { Capital }\end{array}$ & Culture & Company Value Campaign & \begin{tabular}{|l|} 
(Jumlah kegiatan/ \\
Target kegiatan)*100\%
\end{tabular} & $\%$ & $\begin{array}{l}\text { Kegiatan sesuai target }= \\
100 \%\end{array}$ & $5 \%$ & \begin{tabular}{l|l}
$3,50 \%$ & $T$ \\
\cline { 2 - 2 } & $F$ \\
\end{tabular} & \begin{tabular}{|l|} 
Target \\
Realisasi \\
Pencapaian \\
\end{tabular} & \begin{tabular}{|l|}
$5,00 \%$ \\
$3,50 \%$ \\
$70,00 \%$ \\
\end{tabular} \\
\hline & & & & Pelaksanaan Training Plan & \begin{tabular}{|l} 
(Jumlah kegiatan/ \\
Target kegiatan)* $100 \%$
\end{tabular} & $\%$ & $\begin{array}{l}\text { Kegiatan sesuai target }= \\
100 \%\end{array}$ & $10 \%$ & \begin{tabular}{l|l}
\multirow{2}{*}{$7,33 \%$} & $\frac{T}{1}$ \\
\cline { 2 - 2 } & $F$ \\
\end{tabular} & \begin{tabular}{|l|} 
Target \\
Realisasi \\
Pencapaian \\
\end{tabular} & \begin{tabular}{|l|}
$10,00 \%$ \\
$7,33 \%$ \\
$73,33 \%$ \\
\end{tabular} \\
\hline & Pembelajaran \& & & & & & & & & & Target & $10,00 \%$ \\
\hline 4 & Pertumbuhan & Human Canital & Engage \& Competence & New Employee Orientation & Target kegiatan)* ${ }^{*} 100 \%$ & $\%$ & Setiap 3 bulan & $10 \%$ & $10 \%$ & \begin{tabular}{|l|} 
Realisasi \\
Pencapaian
\end{tabular} & $\begin{array}{c}10,00 \% \\
100,00 \% \\
\end{array}$ \\
\hline & & Human Capital & Employee & \begin{tabular}{|l|} 
Pelaksanaan Performance \\
Appraisal (PA)
\end{tabular} & $\begin{array}{l}\text { (Jumlah kegiatan/ } \\
\text { target kegiatan) }{ }^{*} 100 \%\end{array}$ & $\%$ & Januari 2019 \& Juli 2019 & $10 \%$ & $10 \%$ & \begin{tabular}{|l|} 
Target \\
Realisasi \\
Pencapaian \\
\end{tabular} & \begin{tabular}{c|}
$10,00 \%$ \\
$10,00 \%$ \\
$100,00 \%$
\end{tabular} \\
\hline & & & & & & & & & & Target & $10,00 \%$ \\
\hline & & & & Assigment & Target kegiatan) ${ }^{*} 100 \%$ & $\%$ & $100 \%$ & $10 \%$ & $5 \%$ & \begin{tabular}{|l|} 
Realisasi \\
Pencapaian \\
\end{tabular} & $5,00 \%$ \\
\hline & & & & Total & & & & $100 \%$ & \begin{tabular}{|l|l}
$87,81 \%$ & \\
\end{tabular} & & \\
\hline
\end{tabular}




\section{Tahap XI : Rekomendasi Kebijakan Organisasi}

Dalam tahap ini dapat dilakukan analisa hasil pencapaian dalam beberapa perspektif Balanced Scorecard agar dapat memberikan rekomendasi kebijakan organisasi. Total pencapaian KPI dengan metode Balanced Scorecard pada Department Human Resources Management PT XYZ pada tahun 2019 adalah sebesar 87,81\% . Dari pencapaian pada setiap target kerja maka dapat diakukan evaluasi hasil pencapaian kinerja Department Human Resources Management, sbb :

- Terdapat 11 target kerja yang ada pada kategori hijau dimana pencapaian ada dalam batas $76 \%$ - 100\%. Pada kategori ini pencapaian target kerja masih masuk kedalam batas toleransi yang ditetapkan oleh perusahaan, pada kategori ini hanya memerlukan sedikit evaluasi terhadap pencapaian.

- Terdapat 3 target kerja yang berada pada kategori kuning yaitu target kerja Maintain employee turnover dengan pencapaian sebesar $75,00 \%$, company value campaign dengan pencapaian sebesar 70,00\%, dan pelaksanaan training plan 73,33\%. Dengan masukkan ketiga target kerja tersebut kedalam kategori kuning, artinya terdapat kendala dalam pelaksanaan ketiga target kerja tersebut. Demikian beberapa analisa terkait dengan pencapaian masing-masing target kerja :

- Target kerja Maintain employee turnover angka cukup tinggi karena berada pada kisaran $10>X \leq 18 \%$. Sehingga hal bisa menjadi salah satu rekomendasi perusahaan untuk dapat melakukan program Employee Engagement agar angka turnover karyawan dapat diminimalisir.

- Company value campaign dicapai pada angka 70,00\% hal ini tentunya menggambarkan pelaksanaan campaign terkait dengan nilai budaya perusahaan belum maksimal, sehingga pada tahun 2020 perlu adanya program terpadu untuk dapat melakukan campaign nilai-nilai budaya perusahaan.

- Target kerja ketiga yang ada di kategori kuning ini adalah Pelaksanaan Training Plan dengan angka pencapaian sebesar 73,33\%. Dalam target kerja ini ada beberapa kegiatan rencana training yang tidak bisa dijalankan karena pengaturan jadwal training pada tim operasional belum bisa dilakukan. Sehingga hal ini bisa menjadikan sebuah masukan kepada perusahaan bahwa kegiatan training adalah kegiatan wajib yang harus diikuti oleh semua karyawan dan harus mendapatkan dukungan dari top management agar semua karyawan dapat mengikuti program training sesuai dengan jadwal yang telah ditetapkan.

- Pada kategori merah, terdapat 1 target kerja yang pencapaian hanya 50\% yaitu :

- Target kerja Coaching, Project, Assignment sebesar 50\%. Hal ini terjadi karena target kerja tidak dilakukan dengan konsisten. Pada target kerja ini proses coaching, project dan assignment seharusnya dilakukan setiap 3 bulan sekali untuk level staff dan supervisor. Namun karena target ini tidak dilakukan secara konsisten, maka target kerja tidak dapat dicapai secara penuh. Hal ini menjadikan salah satu rekomendasi bagi perusahaan untuk dapat melakukan evaluasi dalam pelaksanaan program tersebut.

\section{KESIMPULAN \& SARAN}

\section{Kesimpulan}

Dari analisa terkait penerapan Balanced Scorecard pada Department Human Reources Management, maka disampaikan beberapa kesimpulan, sbb :

1. Penerapan Balanced Scorecard merupakan salah satu sarana pengukuran kinerja yang dapat digunakan untuk menganalisa target kerja baik pada perusahaan maupun pada 
department yang ada dalam perusahaan. Pengukuran dilakukan berdasarkan pada visi misi serta peta strategi pada department terkait.

2. Penerapan strategi pada visi misi department Human Resouces Management sebagai business partner dalam mengelola dan mengembangkan karyawan belum dapat berjalan optimal karena masih terdapat pelaksanaan target kerja dalam persektif proses bisnis internal dan persektif pembelajaran dan pertumbuhan yang belum terlaksana dengan baik dan konsisten.

3. Sebagai department yang berperan sebagai business partner dalam mengelola dan mengembangkan karyawan, Department Human Resources Management mempunyai peran yang sangat besar dalam perspektif pembelajaran dan pertumbuhan. Namun dengan penerapan konsep Balanced Scorecard dapat menyeimbangkan persektif lainnya agar setiap persepktif saling mendukung untuk dapat mencapai visi misi dan strategi yang telah ditetapkan.

4. Pelaksanaan target kerja yang belum tercapai secara optimal memerlukan evaluasi dan monitoring terutama pelaksanaan target kerja yang berkaitan dengan kepatuhan semua karyawan serta kerjasama dengan department lain, misalnya pada target kerja pelaksanaan rencana training. Hal ini memerlukan komitmen dari semua karyawan agar pelaksanaan target kerja tersebut dapat tercapai dan memberikan pengaruh terhadap pelaksanaan visi misi perusahaan secara keseluruhan.

\section{Saran}

Dengan adanya beberapa kesimpulan diatas, dapat dipahami bahwa Department Human Resources Management mempunyai peran sebagai Business Partner dalam mengelola dan mengembangkan karyawan sehingga kedepannya perlu dilakukan evaluasi dan monitoring pada target kerja yang mempunyai pengaruh yang sangat besar dalam pencapaian visi misi serta strategi Department Human Reources Management, terutama dalam penerapan Company Culture Campaign serta pelaksanaan Training Plan. Untuk mempermudah pelaksanaan target kerja tersebut, setiap tahun perlu dilakukan komitmen pelaksaaan dengan department-department terkait, sehingga target kerja dapat diimplementsikan dengan optimal.

\section{DAFTAR PUSTAKA}

Ali, Hapzi. 2018. Modul 9 SM, Canvas Business Model, Diversification and Balance Scorecard. David, Fred R., 2011. Strategic Management: Concept and Case. 13 th. Ed. Pearson. Education, Upper Saddle River, New Jersey.

Kaplan, R. S. dan David P. Norton. 2000. Balance Scorecard: Menerapkan Strategi Menjadi Aksi, Terjemahan: Pasla Yosi Peter R. Penerbit Erlangga. Jakarta.

Mulyadi. 2001. Balanced Scorecard: Alat Manajemen Kontemporer untuk Pelipatganda Kinerja Keuangan Perusahaan. (edisi ke-2). Jakarta: Salemba Empat.

Pearce, J. A \& Robinson, R.B (PR), Strategic Management; Formulation, Implementation and Control, Irwin Mc Graw-Hill Inc., Singapore, 20132.

Thompson, A. A \& Strickland, A.J (TS), Strategic Management; Concepts and Cases, 11th edition, Irwin Mc Graw-Hill Inc., Singapore, 2008. 